Proceedings

\title{
Public Perception and Quality of Public Open Spaces- Case Study of City and Community Level Parks in Amritsar City
}

\author{
Gulpreet Kaur 1, Sakshi Sahni ${ }^{2, *}$ \\ Assistant Professor; gulpreetk3@gmail.com \\ 2 Assistant Professor; sakshisahni2000@gmail.com (Corresponding Author)
}

Citation: Kaur, G.; Sahni, S. 2022, Public Perception and Quality of Public Open Spaces- Case Study of City and Community Level Parks in Amritsar City. SUPTM 2022 conference proceedings sciforum-053013. https://doi.org/10.31428/10317/10577

Publisher's Note: UPCT and Sciforum stays neutral with regard to jurisdictional claims in published maps and institutional affiliations.

Copyright: (c) 2022 by the authors. Submitted for possible open access publication under the terms and conditions of the Creative Commons Attribution (CC BY) license (https://creativecommons.org/license s/by/4.0/).

\begin{abstract}
The rapport between public open spaces and public contentment eventually determines the quality of life for people residing in large and dense cities. Good quality open space in urban area is pivotal for well-being of individuals. However, there is a huge gap between envisioned design of public open spaces and satisfaction level of users. Therefore, this paper aims to understand and investigate ways in which users of all age groups and genders perceive public open spaces taking five parameters like access and linkages; safety and security; comfort; attractiveness. The methodology follows convergent approach which includes mixed research methods using qualitative and quantitative analysis. Research focuses on city and community level parks of Amritsar city. Results of study can help in providing better planning and designing of open spaces in terms of infrastructure as per the preferences of varied users.
\end{abstract}

Keywords: Public Open Space, Public Perception, City and Community Parks, Infrastructure, Amritsar.

\section{Introduction}

Quality of the public open spaces in urban areas can be judged by the attribute that how long users stay at these places and the choice of activities performed by people in these public spaces. Therefore, the quality of public open spaces is utterly related to people's need and perception [1]. If these spaces will not be perceived usable by the users, then these spaces will become redundant. The ripple effect of inclusively designed public open spaces can be seen in the social, economic, healthy and environmental life of urban areas. Just like the water, sewerage, drainage, electricity, telecommunications, education and healthcare facilities are considered as the key public facilities and services, likewise, the role of public open spaces is also important in maintaining the quality of life in an urban area $[2,3]$.

Therefore, in this context, the central focus of study is to explore use and perception of public open spaces such as community and city level parks in order to get the broader idea of how these open spaces are being used and perceived by the users of all age groups. The study also attempts to identify the reasons that encourage and discourage the public to use these open spaces.

This paper stressed on the need to enhance public open spaces within Amritsar city with an objective to make it more vibrant, dynamic, attractive and xenodochial keeping in mind users' perception of public open spaces, satisfaction level and need of people.

\section{Study Area}

The study sites are located in the heart of Amritsar City. Amritsar is one of the leading cities of Punjab with a population of 11.32 Lakh and $13 \%$ of the total urban population of Punjab lives in Amritsar [4]. Population density of Amritsar has increased six times from 1,190 persons per sq. $\mathrm{km}$ in 2001 to 7,137 persons per sq. $\mathrm{km}$ in 2011 [4]. Congestion especially in the core areas, and increase in concrete structures, lack of open spaces, urban sprawl and no mass space relationship can be witnessed in the city. As per the prescribed URDPFI standards the area under recreation or green spaces should be $20-25 \%$ but presently only $1.5 \%$ of the area is under green spaces which is negligible as compared to the 
standards [5]. It reflects the picture of a city as concrete jungle in which exiguous open spaces, especially the green space is there resulting the city to become a heat island [6]. Amritsar badly lacks in provision of public open spaces which has affected adversely the quality of life of local residents. Therefore, it necessitates need of public open spaces to enhance livability in the city.

In study, four public open spaces are taken at two levels i.e. city level and community level. There are two city level parks such as Company Bagh and Gol Bagh and two community level parks such as Amrit Anand Bagh and Sakatri Bagh (Figure 1).

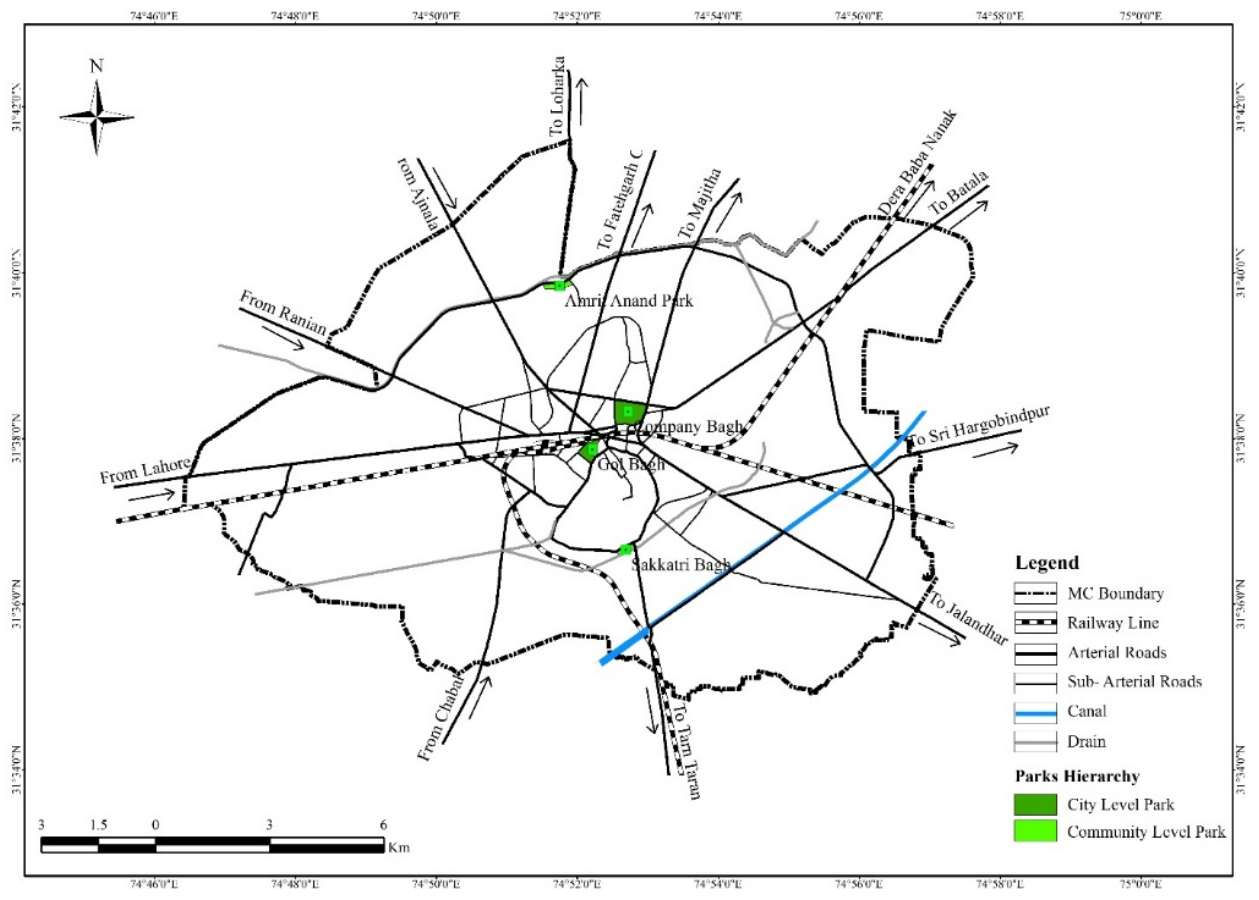

Figure 1. The Distribution of City and Community Level Parks (Study Area) in Amritsar City

\section{Data Collection Methodology and Questionnaires}

In order to assess public spaces various research tools, techniques and methods have been used. The methodology follows convergent approach which includes mixed research methods using qualitative and quantitative analysis. Study involves triangulation of various sources of data collection such as observation and questionnaire survey (Figure 2).

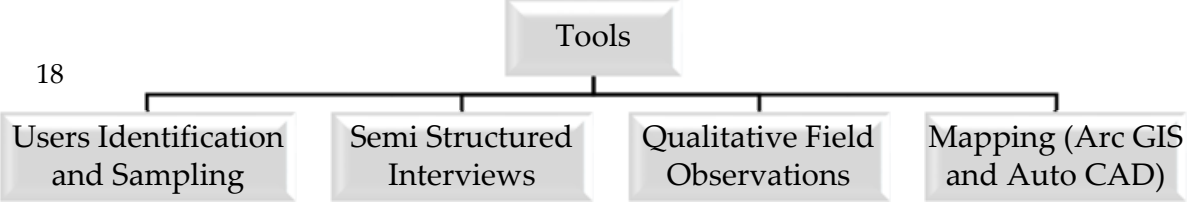

Figure 2. Tools and Methods for Data Collection and Analysis

The collection of data was carried out using questionnaires to 400 respondents visiting city and community level parks. The respondents during data collection process were people who were performing their activities in these study areas. Respondents were selected randomly in each activity zones from study area.

The questionnaire prepared was divided into a number of sections such as-

(1) the profile of the user;

(2) the perception about relationship between open space and selected parameters such as access and linkages; safety and security; comfort; attractiveness.

(3) the user's level of satisfaction.

The analysis from these questionnaires will describe socio-economic profile of users, the duration, frequency and the variation of activities. 
Data collection took place on weekends and weekdays during peak time, from $8^{\text {th }}$ to 1 $20^{\text {th }}$ February 2021 and interview ranged from 20 to 45 minutes (33 minutes' average).

The questions have negative, positive as well as neutral answers.

The primary data has helped in exploring the attitudes, use and perception of the public open spaces. The use of open-ended questions was their which was beneficial to capture the respondents' own words and insight which encourage them to use these public spaces and this open framework allows two-way communication.

Some of the secondary data were also collected from newspapers and internet regarding issues and crimes happened at study areas in the past time. The information gathered from these discussions helped to build a solid basis for the further research.

\subsection{Data Analysis, Compilation and Mapping}

After data collection, the next stage in the research logically appears is the data analysis stage. After collection of data, the process of analyzing data commenced, for quantitative data analysis; Microsoft excel was used as a tool of examining data. Later, Arc GIS and Auto CAD were used to produce the maps.

\section{Results}

Parameter like access and linkages is further assessed on the basis of road links or connectivity, accessible entry point, public transport system and parking facility. The results of survey conducted from users reveals that $76 \%$ of them are satisfied with the access and linkages of both the city level parks because they are well connected from all the 4 sides with three entrances and has a good connectivity. City parks are connected properly with surrounding neighborhoods and are easily accessible due to their central location. However, $24 \%$ of the users are not satisfied because, the Gol Bagh has main access only through Durgiana Mandir Road which has a lot of congestion and parking of Gol Bagh is being misused by the local residents, autos and the taxis for tourists. In the peak hour, there is no place for the users to park their vehicles. Moreover, no access has been provided for persons with disability. There are bollards at the starting of footpath which creates problems for the aged people, as per the survey from elderly users, and they do not perceive it comfortable.

In the community level parks, $36 \%$ of the users are not satisfied because Rose Garden do not have the availability of PTS like autos or BRTS as it has its main entrance through National Highway. The other reason for the dissatisfaction of the users is that Amrit Anand Park is in the extreme north, so it is not approachable by the people in South Amritsar and similarly is the case with Sakkatri Bagh, as it is not accessible by the population living in the north. Sakkatri Bagh being smaller and because of its secluded location from a major part of the city, it is perceived as a private park by other people of the city and hence used only by the people living in close vicinity with it (Table 1).

Table 1. Results of User Perception Survey

\begin{tabular}{lcccc}
\hline \multicolumn{1}{c}{ Parameters } & \multicolumn{2}{c}{ City Level Parks (\%) } & \multicolumn{2}{c}{ Community Level Parks (\%) } \\
& Satisfied & Not Satisfied & Satisfied & Not Satisfied \\
Access and Linkages & 76 & 24 & 64 & 36 \\
Safety and Security & 78 & 22 & 67 & 33 \\
Comfort and Attractiveness & 87 & 13 & 93 & 7
\end{tabular}

Further, safety and security are further assessed on the basis of attributes such as lighting, surveillance, helpline number, and sightline. In city parks, children park is completely out of sightline as it has huge trees all around. The main reason is the placement of the children park is not correct, as it is placed in an isolation from the whole park, which do not provide the sense of security to parents. Moreover, the other reason is that the tress is not being maintained by the gardener as they were not cut properly.

Lighting and passive surveillance is one of the ways to make public spaces feel safer. At Company Bagh, there are proper streetlight, but because its huge area and some of the 
dark area, teenage girls do not prefer to go as they do not feel safe to come after $7 \mathrm{pm}$ because of drunken people due to presence of clubs. Company Bagh has proper illuminated lights but at some points of the park, lights are not properly working, and the main reason is vandalism. However, the city and community level parks both lack in the infrastructure such as CCTV cameras for the supervision.

Under the attributes of comfort and attractiveness, it was found that both levels of park were having better sitting furniture and basic amenities like toilets. Therefore, the availability of this basic infrastructure allows users to stay for a longer period of time. But the major problem is that the toilets are not well maintained and are unhygienic. At Company Bagh, toilets for disabled persons are present but they are not as per standard as they are constructed on raised platform which is not accessible by persons with disabilities and wheelchairs. Even toilets at Gol Bagh toilets are locked and not in use.

All the age groups have the provision of different activities such as skating, badminton, lawn tennis etc. For the adult's, the open gyms are present and yoga classes are going on. For elderly there is adequate space for sitting and relaxing. During the survey, several groups of elderlies were found playing cards and other games at many points of the park.

In community level Sakkatri Bagh, drinking water is not present, which is basic requirement in the parks, especially in summers. The user's fee is applicable on the usage of toilets, but still they are not maintained. Stinking toilets make the place and its surroundings unhygienic at Sakkatri Bagh.

\section{Conclusions}

Public open and green spaces play an indispensable role in amplifying an active lifestyle for urban dwellers. The findings from the study suggest that the public open spaces should be designed such a way, that these spaces should be cosmopolitan in nature as well as inclusive. It is imperative to go into the nitty gritty of the situation, while keeping in mind the broader picture. The three chief elements of the public realm design which are needed to be well connected in order to make any public space successful should emerged as a PPP mode i.e. People, Place and Programs. The people will be the users of the space, place will be the space itself and programs will be introduced to keep the users engaged in these public open spaces. With all these elements people can assume the space to be more belongs and contented.

From the study findings, it is clear that there is absolutely necessary to reimagine the concept of public open spaces and make them more creative and captivating especially when there is a lot of space crunch in the city. This is really thoughtful, and it leads us to people centric designs.

Funding: This research received no external funding.

Acknowledgments: The authors are highly indebted to the public who gave their valuable time for recording of feedback for the perception analysis.

Conflicts of Interest: The authors declare no conflict of interest.

\section{References}

1. Bele.A, Wasade N., 2018, “Perception, Use and Experience of Urban Open Spaces-Case Studies of Neighborhood Public Parks in Nagpur", International Journal of Science and Research, Volume 07, Issue 09.

2. Mohd. Shoeb Jafri, Mohd. Rajaullah, 2018, “Evaluating the Urban Green Spaces: Benefits and Issues”, International Journal of Engineering Research, Volume No.7, Issue Special 3, pp: 269-273.

3. Sutera Hotel, Sutera Harbour, Kota Kinabalu, Sabah, Malaysia, 2014, "Quality of Life in the Built \& Natural Environment", Procedia - Social and Behavioral Sciences, 153, pp. 585 - 594.

4. Amritsar District Census Handbook, 2011, Series-04, Part XII-B, Directorate of Census Operations, Ministry of Home Affairs, Government of Punjab, Chandigarh.

5. Amritsar Master Plan, 2010, Punjab Urban Development Authority (PUDA), Government of Punjab, Chandigarh.

6. Khaitan S. Shubham, 2013, Conference Paper on "Impact of Urbanization on Environs of Amritsar City", Changing Spectrum of Human Settlements and Planning Education. 